\title{
Effects of occupational dust exposure on the health status of portland cement factory workers
}

Manjula R., R. Praveena1, Rashmi R. Clevin', C. H. Ghattargi,

\section{A. S. Dorle, D. H. Lalitha}

Departments of Community Medicine and ${ }^{2}$ Physiology, S. Nijalingappa Medical College, Bagalkot, ${ }^{1}$ Community Medicine, Belgaum Institute of Medical Sciences, Belgaum, Karnataka, India

Address for Correspondence: Dr. R. Manjula,

C/O S. S. Belagal, $8^{\text {th }}$ Main, "Pratiksha", Vidyagiri, Bagalkot - 587 102, Karnataka, India. E-mail: manjupushya2000@ yahoo.com

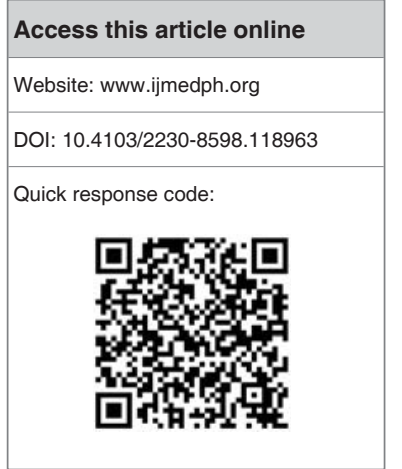

Introduction: Chronic exposure to Portland cement dust has been reported to lead to greater prevalence of various clinical conditions (includes both respiratory and non-respiratory). These conditions are consistently associated with the degree and duration of exposure. Regular use of appropriate personal protective equipment if made available at the work site could protect the cement factory workers from adverse health effects. Objective: To study the morbidity profile of the cement factory workers.Type of Study: Retrospective cohort study. Material and Methods: This study was conducted in the Portland Cement Factory in North Karnataka. Data was collected using predesigned questionnaire by personal interview method and clinical examination. A total of 64 male workers are randomly selected who are working in various departments like crushing, raw/cement mill, rotary kiln and packing department. Equal number of unexposed controls was selected from the area atleast $5 \mathrm{kms}$ from the factory and those who are not exposed to cement dust in the past, who are matched for age, Socio economic status and smoking with the exposed population. Statistical Analysis: Chisquare test for qualitative data and unpaired $t$ test for quantitative data using Epi info. Results: A total of 64 male workers and equal number of matched controls who are not exposed to the cement dust were included in the study. Among exposed maximum of $36 \%$ were employed in Crushing department, 25\% each in Packing and cement/raw mill. Systolic and Diastolic blood pressure was found to be higher among the exposed, which is statistically highly significant $(p<0.001)$. There is significant increase in weight among exposed $(p<0.001)$. Maximum $29(45.3 \%)$ of the workers had stuffy nose and epistaxis when compared to unexposed with Relative risk(RR) of 2.6, followed by Dermatological complaints and lower respiratory complaints with RR of 2.18 and 2.3 respectively. Conclusion: Personal protective equipment should be made available at the workplace and educate the personnel to use them. Extensive research is necessary to improve the technical preventive measures that will reduce the risk of occupational health hazards.

Key Words: Portland cement dust, occupational health hazard, COPD.

\section{INTRODUCTION}

Chronic exposure to Portland cement dust has been reported to lead to greater prevalence of various clinical conditions which includes both respiratory and non-respiratory systems involvement. These conditions are consistently associated with the degree of exposure. Regular use of appropriate personal protective equipment, if available at the work site could protect the cement factory workers from adverse health effects. ${ }^{[1]}$

The pollutants in the cement industry are emitted from the various production processes from the material such as the raw material, crusher, rotary kiln, cranes, mills, storage silos and packing section, etc., Airborne respirable dust levels from less than 5 to more than $40 \mathrm{mg} / \mathrm{m}^{3}$ have been recorded in the work place air of cement factory workers. The aerodynamic diameter of the cement dust ranges from 0.05 to $20 \mu \mathrm{m}$, making the whole respiratory tract a target for cement deposition. ${ }^{[2]}$ 
The essential constituents of Portland cement are tricalcium silicate and dicalcium silicate, with varying amount of alumina, tricalcium aluminate and iron oxide and low concentration of hexavalent chromium. Contents of Portland cement includes mixtures of calcium oxide- $62-66 \%$, silicon oxide-19-22\%, Aluminium tri oxide- $4-8 \%$, ferric oxide- $2-5 \%$, Magnesium oxide- $1-2 \%$ and also contains selenium, Thallium, and other impurities. ${ }^{[3]}$

Portland cement is also an artificial cement, there are different types of Portland cement such as ordinary, or rapid hardening, sulfate resisting, white colored, low heat, masonry, hydrophobic, water-repellant expanding and non-shrinking, high aluminium, blast furnace and oil wall cement. Portland cement is produced in cement factories under consideration of different substances especially the limestone and clay, which are heated to approximately $1250^{\circ} \mathrm{C}$ for a period of 90 minutes. The final product is obtained by grinding its contents with $5 \%$ gypsum. ${ }^{[4]}$

The main route of entry of cement dust particles in the body is the respiratory tract or the gastrointestinal tract or both by inhalation or swallowing. This has been identified as a skin irritant, which causes itching, skin allergy, boils, and burn. In experimental animals those who were fed with cement dust for 42 days found that body weight reduction, osteonecrosis, thinning of cortex, and reduction of epiphyseal cartilage.

Even in the twenty-first century, millions of people are working daily in a dusty environment. They are exposed to different types of health hazards like fumes, gases, and dust which are risk factors in developing occupational lung diseases.

For variety of reasons, like ignorance or the non-availability of personal protective devices, the workers do not adequately protect themselves through personal protective device..$^{[1]}$

\section{MATERIALS AND METHODS}

This is a retrospective cohort study conducted in the Portland Cement factory in north Karnataka during December 2010 to March 2011.

After obtaining permission from the concerned authorities like factory proprietor, human resource development officer, etc., for conducting the study, workers list was obtained from them. About 150 workers are working regularly in various shifts and about 70 workers were undergoing initial training. Seventy trainees were excluded from the study. We selected 100 workers randomly to participate in the study, who worked in crushing department, raw/cement mill, rotary kiln and packing department for atleast 5 years. Medical records of these workers were scrutinized to determine the health conditions of the workers. The workers who gave history of respiratory and non-respiratory problems like allergy, asthma before the employment during preplacement examination were excluded from the study. But 64 were included in the study who are eligible, readily participated by giving consent and who had given complete history and examination was done.

Equal number of unexposed people were randomly selected from the area, which is atleast $5 \mathrm{~km}$ away from the factory and those who are not exposed to cement dust in the past, these controls were matched for age, socio-economic status, and smoking with

\begin{tabular}{|c|c|c|}
\hline Site & No. & $\%$ \\
\hline Crushing department & 23 & 36 \\
\hline Rotary kiln & 9 & 14 \\
\hline Packing department & 16 & 25 \\
\hline Cement/Raw mill & 16 & 25 \\
\hline
\end{tabular}

\begin{tabular}{|c|c|c|c|c|}
\hline Parameters & Exposed & Unexposed & I & $P$ \\
\hline Age & $44.2 \pm 8.6$ & $41.8 \pm 7.8$ & 1.66 & $>0.05$ \\
\hline Weight in $\mathrm{kg}$ & $68 \pm 11.3$ & $64 \pm 10.8$ & 2.05 & $<0.05$ \\
\hline Height in $\mathrm{cm}$ & $170.8 \pm 7.2$ & $173.2 \pm 6.8$ & 1.95 & $>0.05$ \\
\hline Systolic BP & $134.16 \pm 12.3$ & $128.14 \pm 8.3$ & 3.23 & $<0.001$ \\
\hline Diastolic BP & $94.4 \pm 11.3$ & $86.12 \pm 6.32$ & 5.14 & $<0.001$ \\
\hline $\begin{array}{l}\text { Cigarette smoking } \\
\text { (pack years) }\end{array}$ & $6.1 \pm 4.2$ & $5.8 \pm 4.8$ & 0.37 & $>0.05$ \\
\hline
\end{tabular}

Values are expressed as mean $\pm \mathrm{SD}, P<0.05$ is considered as significant, $\mathrm{BP}=\mathrm{Blood}$ pressure

\begin{tabular}{|c|c|c|c|c|c|}
\hline \multirow[t]{2}{*}{ Disease conditions } & \multicolumn{2}{|c|}{ Exposed } & \multicolumn{2}{|c|}{ Unexposed } & \multirow{2}{*}{$\begin{array}{c}\text { Relative } \\
\text { risk }\end{array}$} \\
\hline & No. & $\%$ & No. & $\%$ & \\
\hline Stuffy nose/epistaxis & 29 & 45.3 & 2 & 3.1 & 2.6 \\
\hline Lower respiratory problems* & 24 & 37.5 & 2 & 3.1 & 2.3 \\
\hline $\mathrm{GI}_{\text {problems }}^{\dagger}$ & 14 & 21.8 & 2 & 3.1 & 1.96 \\
\hline Oral problems ${ }^{\ddagger}$ & 24 & 37.5 & 3 & 4.6 & 2.2 \\
\hline Musculoskeletal problems $\S$ & 12 & 18.8 & 3 & 4.6 & 1.7 \\
\hline
\end{tabular}

*Lower respiratory problems like cough with or without expectoration, rhonchi, crepitations, abnormal respiratory sound on auscultation, ${ }^{\dagger}$ Gastrointestinal problems like diarrhea, constipation, dysentery, hematochezia, ${ }^{\ddagger}$ Oral problems like aphthous ulcers, tooth caries, plaques, bleeding gums, §Musculoskeletal problems like muscle ache, joint pains, myalgia

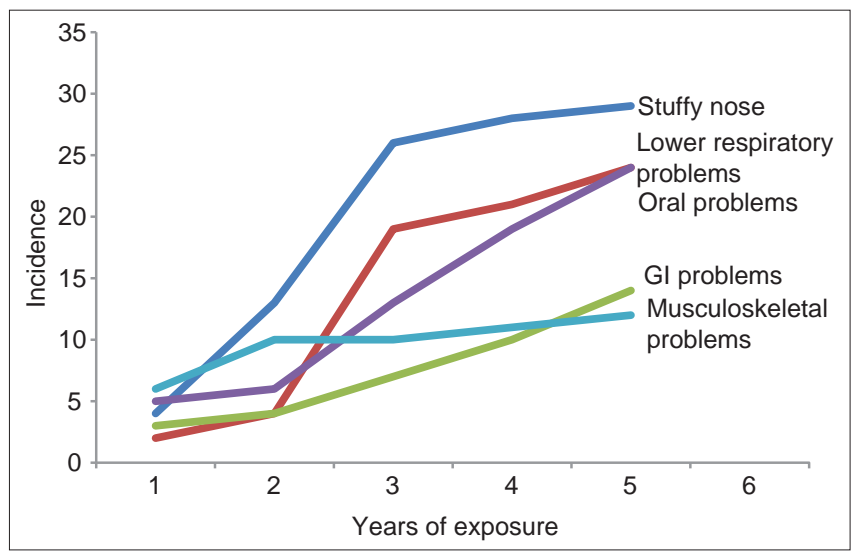

Figure 1: Cumulative incidence of various clinical conditions 
the exposed population.

Data was collected regarding general demographic profile, smoking, clinical signs, and symptoms with the help of predesigned questionnaire by personal interview method and clinical examination. After obtaining height and weight BMI was calculated as weight in $\mathrm{kg} /$ height in $\mathrm{m}^{2}$. Information was collected regarding the use of personal protection equipment (work coveralls, gloves, dust masks, ear plugs, and safety shoes) while at work, it was found that none of the respondents used any of the above mentioned personal protective devices. Few of the respondents covered their nose and mouth with towel/hand kerchief which itself was dusty and had the stains of black-colored nasal secretions.

Statistical analysis was conducted using EPI-Info software, Chi-square test for proportions, unpaired ' $t$ ' test for quantitative data. And relative risk was calculated for clinical conditions among exposed and non-exposed.

\section{RESULTS}

A total of 64 male workers and equal number of matched controls who are not exposed to the cement dust were included in the study. Among exposed maximum of 36\% were employed in Crushing department, 25\% each in packing and cement/raw mill [Table 1]. Systolic and diastolic blood pressure was found to be higher among the exposed, which is statistically significant $(P<0.001)$. There is significant increase in weight among exposed $(P<0.001)$ [Table 2]. Maximum 29 (45.3\%) of the workers had stuffy nose and epistaxis when compared to unexposed with Relative risk (RR) of 2.6, followed by dermatological complaints and lower respiratory complaints with RR of 2.18 and 2.3, respectively [Table 3].

\begin{tabular}{lcc}
$\begin{array}{l}\text { Table 4: Demographic characteristics of study } \\
\text { subjects }\end{array}$ & No \\
\hline Characteristics & & \\
\hline Religion & 52 & 81.2 \\
Hindu & 12 & 18.8 \\
Muslim & & \\
Place of residence & 43 & 67.2 \\
Urban & 21 & 32.8 \\
Rural & & \\
Type of family & 24 & 37.5 \\
Nuclear & 40 & 62.5 \\
Joint & & \\
Educational status & 1 & 1.6 \\
Primary & 9 & 14 \\
Secondary & 24 & 37.5 \\
Pre-university & 30 & 46.9 \\
Degree & & \\
Socioeconomic status & 26 & 40.6 \\
II & 37 & 57.8 \\
III & 1 & 100 \\
IV & 64 & \\
Total & &
\end{tabular}

Cumulative incidence of the clinical conditions for the period of 5 years is represented [Figure 1].

\section{DISCUSSION}

In the present study it was found the health profiles of the cement factory workers were very poor and the living condition in the working environment was poor. Cement factory workers were exposed to dust at various manufacturing and production process such as quarrying, handling, grinding, shifting, packing, and transportation. These workers were compromised to work in such situation may be due to poor socioeconomic status and low education level [Table 4], similar finding was observed by the Mwaiselage J in their study in Tanzania. ${ }^{[2]}$

There was no difference in the occurrence of diseases in the exposed workers who are working in different sections of work through the level of exposure is not same in all the sections. This could be because of workers were reshuffled in different shifts to different sections, hence overall exposure of the workers in our study remained same.

In the physical parameters, it was found that there is significant difference in body weight of exposed compared to unexposed [Table 2], but it was found that no difference by Al-Neaimi in the study conducted in UAE. ${ }^{[1]}$ There was significant increase in systolic and diastolic blood pressure among exposed workers when compared to non exposed anyway it was found that there is no difference by Al-Neiami. ${ }^{[1]}$ Intratracheal administration of cement dust in animal studies have shown that it increased fibrosis of heart and also increase in collagen in vessels, may lead to increase in blood pressure. ${ }^{[5]}$

In the clinical parameters, among the cement dust-exposed workers $45.3 \%$ of them had upper respiratory complaints like stuffy nose, running nose and allergic rhinitis, whereas the non-exposed it was only $3.1 \%$ with relative risk of 2.6 [Table 3]. Similarly it was found by many researchers who found stuffy nose was relatively more among exposed workers. ${ }^{[2]}$ The aerodynamic diameter of cement particles range from 0.05 to $10 \mu \mathrm{m}$, and main route of entry of this dust is through inhalation and swallowing. The physical properties that are of importance include particle size, density, shape, penetrability, surface area, electrostatic charge, and hygroscopicity. All particles with an aerodynamic diameter in excess of $10 \mu \mathrm{m}$ are deposited on the mucous membrane of the nose and trachea. This is an irritant and also causes allergy and various manifestations of upper respiratory tract. ${ }^{[6,7]}$

In the present study, the gastrointestinal problems among the exposed group were found to $21.8 \%$ whereas among the unexposed it was $3.1 \%$ with relative risk of 1.06 for the exposed population. In this study the spectrum of presentation includes diarrhea, constipation, hemorrhiods, etc., other similar studies have found that cement dust caused a stomach cancer. ${ }^{[7]}$ Hence, this workers need to be subjected to lab investigations to rule out malignancy of GIT. 
Substantial number $(37.5 \%)$ of the exposed workers had oral problems which is very low among unexposed (4.6\%). The clinical manifestations include Aphthous ulcer, caries, plaques and unhealthy gums. Since the cement dust can enter through swallowing. ${ }^{[6,7]}$ A study conducted by Tuominen observed the effect of cement dust on the tooth surface loss was higher. ${ }^{[8]}$ They also found that workers exposed to dust revealed a high prevalence of dental caries with number of decayed, missing, and filled surfaces along with poor periodontal conditions.

In our study, $18.8 \%$ of the exposed group had musculoskeletal problems, whereas $4.6 \%$ of the non-exposed had this problem with relative risk of 1.7. Similar studies have shown that $7.04 \%$ had musculoskeletal problems among exposed though not significant when compared to non-exposed. ${ }^{[9]}$ Studies conducted in experimental animals have shown that bioaccumulation of industrial cement dust components which is inhaled, accumulated in bones. ${ }^{[10]}$ In another study the weanling pig fed with cement dust for 42 days found that body weight gain was suppressed, observed lesions of the humerous bone along with osteonecrosis, thinning of cortex and reduction of epiphyseal cartilage. ${ }^{[11]}$

In the present study, $37.5 \%$ of the exposed population had lower respiratory signs and symptoms like cough, with or without expectoration, wheeze, crepitations, etc., which were only $3.1 \%$ among unexposed population. The dust particles ranges from 3 to $10 \mu \mathrm{m}$ in diameter can be deposited throughout the tracheobronchial tree. Particles between 0.1 and $3 \mu \mathrm{m}$ in diameter are deposited in alveoli resulting in the range of clinical presentation. The pathogenesis is most probably due to its irritating, sensitizing and pneumonocytic properties. ${ }^{[3,12]}$ Al-Neaimi YI conducted a study in UAE, found that around $30 \%$ of the exposed had cough, $25.4 \%$ had phlegm, 7.5\% had wheeze and $20.9 \%$ had dyspnea. ${ }^{[1]}$ Whereas Neghab M in their study observed that $28.4 \%$ had wheezing, $17 \%$ with breathlessness, 31\% had cough. ${ }^{[13]}$ In another study byAbrons HL found that the exposed population had respiratory complaints in a range of $8-15 \% \cdot{ }^{[14]} \mathrm{Al}-\mathrm{Neaimi} \mathrm{YI}$ also studied respiratory function test to know the type of respiratory illness (obstructive/restrictive), but this was not done in our study as a limitation of the study. Many studies have found that exposed workers had restrictive lung diseases after exposure to the cement dust for a particular time period ${ }^{[1,6,7]}$ with decreased $\mathrm{FVC}, \mathrm{FEV}_{1}$ and an increase in $\mathrm{FEV}_{1} / \mathrm{FVC}$ ratio. Few studies have found that cement mill workers suffered from chronic bronchitis, ${ }^{[15-17]}$ which was also noticed in our study. In a study conducted in Tanzania detected lower respiratory complaints in (41.2-43.1\%) among exposed compared to low exposed (6.0-9.1\%). ${ }^{[2]}$ In Malaysia lower respiratory complaints was $25 \%$ and chest tightness in $19.4 \% \cdot{ }^{[18]}$ These symptoms and signs were exaggerated among those exposed group who are smokers and exposure to domestic smoke. Respiratory tract disorders, the most important group of occupational diseases in the cement industry are the result of inhalation of airborne dust. Chronic bronchitis often associated with emphysema has been reported as the most frequent respiratory disease. ${ }^{[19]}$ Additionally silicosis followed by mixed dust pneumoconiosis have been claimed greatest risk for cement factory workers. ${ }^{[20]}$

Cement industries in the developed countries are more efficient in dust control measures using methods such as enclosure of dust, emitting machinery, conveyor belts and its transfer points, improved general mechanical ventilation in the work areas: Local exhaust ventilation from the crusher and packing machinery: Replacement of pneumatic packing machine with automatic impellar driven packing machine; wet dust suppression during cleaning activities; greater diligence in maintenance of machinery to prevent dust release; regular use of high quality personal protective respiratory equipment and influencing workers behavior by training and education. ${ }^{[21]}$

\section{CONCLUSIONS}

In the present study, the workers were suffering from varied health problems, which was relatively more than the general population. It also suggests the cement factory workers were exposed to the dust in the environment, with minimum or no protective equipments. Hence, there is an urgent need to look into the matters by the concerned authority to improve the living conditions. Health education was given regarding the personal protection measures, but needs reinforcement in the form of regular such education programs and legislative laws. Keeping in view the hazards of cement dust it is advisable, therefore the cement factory management, their workers and health officials should work together to adopt technical preventive measures such as well-ventilated work areas and workers should wear appropriate apparel, mask, safety goggles, gloves, ear plugs and gum boot is also important that cement mill workers must undergo pre-employment and periodic medical surveillance test. These measures would help to identify susceptible workers in due time and improve the technical preventive measures that will decrease the risk of occupational hazards in the cement industry workers.

\section{REFERENCES}

1. Al-Neaimi, Gomes J, Lloyd OL. Respiratory illnesses and ventilator function among workers at a cement factory in a rapidly developing country. Occup Med 2001;51:367-73.

2. Mwaiselage J, Moen B, Bratveit M. Acute respiratory health effects among cement factory workers in Tanzania: An evaluation of a simple health surveillance tool. Int Arch Occup Environ Health 2006;79:49-56.

3. Meo SA. Health hazards of cement dust. Saudi Med J 2004;25:1153-9.

4. EL-Sewefy AZ, Awad S, Metwally M. Spirometric measurements in an Egyptian Portland cement factory. J Egypt Med Assoc 1970;53:179-86.

5. Maciejewska A. Experimental silicosis. Analysis of collagen levels in the heart, spleen and liver of rats in experimental silicosis. Med $\mathrm{Pr}$ 1987;38:45-54.

6. Yang CY, Huang CC, Chiu HF, Chiu JF, Lan SJ, Ko YC. Effects of occupational dust exposure on the respiratory health of Portland cement workers. J Toxicol Environ Health 1996;49:581-8.

7. Oleru UG. Pulmonary function and symptoms of Nigerian workers exposed to cement dust. Environ Res 1984;33:379-85.

8. Tuominen M, Tuominen R. Tooth surface loss and associated factory workers in Finland and Tanzania. Community Dent Health 1992;2:143-50.

9. Ansari FA, Bihari V, Rastogi SK, Ashquin M, Ahmed I. Environmental health survey in asbestos cement sheets manufacturing industry. Indian J Occup Environ Med 2007;11:15-20. 
10. Reichrtova E. Biomonitoring of industrial dust on animals. I. Bioaccumulation of dust components. Acta Biol Hung 1986;37:7-12.

11. Pond WG, Yan JT, Hill DA, Ferrell CL, Krook L. Bone lesions in growing swine feed $3 \%$ cement kiln dust as a source of calcium. J Anim Sci 1982;54:82-90.

12. Sheppard D, Hughson WG, Shellito J. Occupational lung diseases. In: La Dou J, editor. Occupational Medicine. USA: Appleton and Lange; 1990. p. 221-36.

13. Neghab M, Choobinah A. Work related respiratory symptoms and ventilatory disorders among employees of a cement industry in Shiraz, Iran. J Occup Health 2007;49:273-8.

14. Abrons HL, Petersen MR, Senderson WT, Engelberg AL, Harber P. Symptoms, ventilator function and environmental exposures in Portland cement workers. Br J Ind Med 1988;45:368-75.

15. Vyskocil J. The problem of chronic bronchitis in cement workers. Rev Czech Med 1962;8:38-52

16. Izycki J, Gielec L, Sulkowski W, Kowalska S. Respiratory tract in workers chronically exposed to cement dust. Med Pr 1979;30:241-6.

17. Laraqui Hossini CH, Laraqui Hossini O, Rahhali AE, Tripodi D, Caubet A, Belamallem I, et al. Respiratory symptoms and ventilator disorders among a group of cement workers in Morocco. Rev Mal Respir 2002;19:183-9.

18. Noor H, Yap CL, Zolkepli O, Faridah M. Effect of exposure to dust on lung function of cement factory workers. Med J Malaysia 2000;55:51-7.

19. Pordan L, Bachofen G. Cement and concrete. In: Stellman JM, editors. Encyclopaedia of Occupational Health and Safety. $4^{\text {th }}$ ed. Geneva: International Labor Organization; 1998. p. 93.44-9.

20. Short SR, Petson KE. Respiratory system; the variety of pneumoconiosis. In: Stellman JM, editor. Encyclopaedia of Occupational Health and Safety. $4^{\text {th }}$ ed. Geneva: International Labor Organization; 1998. p. 10.66-9.

21. Mwaiselage J, Bratveitt M, Moen B, Yost M. Variability in dust exposure in a cement factory in Tanzania. Ann Occup Hyg 2005;49:511-9.

How to cite this article: Manjula R, Praveena R, Clevin RR, Ghattargi CH, Dorle AS, Lalitha DH. Effects of occupational dust exposure on the health status of portland cement factory workers. Int J Med Public Health 2013;3:192-6.

Source of Support: Nil, Conflict of Interest: None declared. 